\title{
Exploring Omani EFL Students' Perceptions of the Newly Adopted Online Learning Platforms at the University of Technology and Applied Sciences-Salalah
}

\author{
Muna Kashoob ${ }^{1} \&$ Rais Attamimi \\ ${ }^{1}$ English Language Center, University of Technology and Applied Sciences, Salalah, Oman \\ Correspondence: Muna Kashoob, English Language Center, University of Technology and Applied Sciences, \\ Salalah, Oman. E-mail: Kashoob.m@sct.edu.om
}

Received: December 30, 2020 Accepted: January 31, 2021 Online Published: February 3, 2021

doi:10.5539/jel.v10n2p28 URL: https://doi.org/10.5539/jel.v10n2p28

\begin{abstract}
Due to the rapid advancement of the relevant technology and the COVID-19 health pandemic, educational institutions have had to adapt to ongoing and ever-changing circumstances at a very rapid rate. Thus, the Moodle and Microsoft Teams platforms are being used by teachers to more directly teach students, as well as fulfilling its initial role in providing a supplementary tool to maintain, the convention of independent learning. The current study explores the perceptions of a group of Omani students who are currently enrolled in the English Language Center of the University of Sciences and Applied Technology, Salalah campus, (hereafter referred to as UTAS) regarding the new online learning platforms, i.e. Moodle and Microsoft Teams. To this end, a questionnaire was adopted from Rojabi's (2020) study to measure the perceptions of the students towards both Moodle and Microsoft Teams platforms. A sample of 100 students was randomly selected from the population. The findings of the study have offered some important suggestions on how to improve the existing online platforms and pave the way for further research to be conducted in the same area.
\end{abstract}

Keywords: English, teaching, learning, technology, microsoft teams, moodle

\section{Introduction}

Technology has made education more comfortable, flexible and available to everyone. Most of the schools, colleges and universities around the world have adopted technology for specific purposes and outcomes intimately involved with teaching and learning. E-learning is one of the most commonly used technological approaches in educational institutions. It may currently be considered as a useful tool for instructors in language classrooms. Accordingly, the implementation of e-learning in teaching for this purpose is rapidly increasing on a global scale. There are intensively programmed applications which can facilitate the learning process, in turn enabling teachers to more creatively and comprehensively develop their lessons.

Concurrently, the unabated spread, and ongoing recurrence of the COVID-19 epidemic in sometimes successive waves around the world has created challenges for the educational sector. One of these challenges is the partial or complete lockdowns of schools, colleges and universities. As a result, the administrations of these educational institutions have maintained the learning process via e-learning applications. Both teachers and students have been compelled to adapt to the new e-learning approaches, upon which they may not have previously been trained.

According to Erarslan and Topkaya (2017) the "e-learning environment, together with the widespread use and availability of internet enhanced computers and smartphones have changed the pace and boundaries of second and foreign language learning, especially on the part of the learners" (p. 82). To overcome the closure of educational institutions, many colleges and universities have continued their core academic learning degree programs by using online platforms. Also, in response to this significant level of demand, many platforms have offered free access to their services. UTAS has adopted Microsoft Teams and Moodle platforms to maintain teaching and learning during this crisis.

It is essential to recognize students' perceptions of Moodle and Microsoft Teams as they play an important role in identifying the extent to which these platforms are successfully employed in enhancing the teaching and learning of English Language in the midst of the COVID-19 pandemic. The findings of the current study will 
contribute to the improvement of the process of e-learning techniques within the current higher education system in the Sultanate of Oman.

\section{Literature Review}

Allen and Seaman (2017) reported that there were six million students who participated globally in at least one higher education online program in 2015, compared to 1.6 million in the year 2002. This simply means that technology effectually promotes human life, and is becoming a more significant factor of one of the more intensively humanistic of the world's professions, the field of education. By taking advantage of technology, most educational activities are now not only carried out in physical classrooms, but they can also be conducted using online platforms.

The concept of e-learning is not new. E-learning has grown extensively in recent years. Thus, e-learning can be defined here as classroom instructions that can delivered online by the use of the Internet or multimedia platforms (Hall, 2003; O'Neill, Singh, \& O'Donoghue, 2004). According to Rayan (2001), e-learning can be employed through "the use of self-paced independent study units, asynchronous interactive sessions" and "synchronous interactive meetings".

Online learning platforms such as Microsoft Teams and Moodle have been used in many educational institutes for the purpose of integrating technology into classroom teaching and learning processes. These learning platforms allow students to interact and collaborate with their teachers and other students in the virtual classroom, as well as to access their courses and assignments. The implementation of online learning platforms has been studied and repoted in several research projects. In a recent study by Alameri, Masadeh, Hamadallah, Ismail and Fakhouri (2020), the students' perceptions of e-learning through using Moodle, Microsoft teams and Zoom platforms have been examined at the University of Jordan. They reported that using Moodle, Microsoft teams and Zoom platforms during COVID-19 pandemic has a positive effect on their self-study and academic achievement in gereneral.

\subsection{Moodle}

Moodle is a well-known online learning platform which is widely used around the world. It was created by Martin Dougiamas and released in 2002. In the words of Moodle creators, it is "a learning platform designed to provide educators, administrators and learners with a single robust, secure and integrated system to create personalized learning environments" (Moodle, 2020). Different educational institutions use Moodle as a main tool to conduct online classes. Unlike other well-known platforms, Moodle is free. It helps create a virtual society where teachers and students can share ideas and knowledge. A multitude of studies have been done on the effectiveness of Moodle when employed by EFL students. Many studies on the applicability of Moodle have focused on the ability of both teachers and students to successfully inplement Moodle in several language education context, as they believe that Moodle enhances the process of language teaching and learning. In Oman, some studies have been conducted related to the use of Moodle in Omani educational institutes. For example, Ahmad and Al-Khanjari (2012) have studied the effect of Moodle on a group of Omani students at Sultan Qaboos University, while they were enrolled in a course entitled "Basic Computing Skills". The findings of their study showed that students were unambiguously positive while they were using Moodle. Furthermore, the students were confident that they deal with a worthy approach to modern teaching and learning, and finally, this led to the conclusion that e-learning is very useful in the Omani EFL context. On the other hand, Al-Ani (2013) has also conducted a study on using Moodle in blended learning environment. A sample of 283 students at Sultan Qaboos University was selected. The main objective of the study was to identify the factors of using blended learning, which could have a tangible effect on students' learning, motivation and communication. The results revealed that using Moodle has a moderate level of effectiveness on students' motivation, students' achievements, and students' communications.

Al Yafaei and Attamimi (2019) explored the integration of Moodle at the English Language Center of the University of Technology and Applied Sciences- Salalah. The results of their study revealed that the integration of Moodle was successful. Despite the fact that there were some factors that hinder the integration of Moodle, the researchers have concluded that Moodle can be used to teach the other skills of the target language. The previous studies, which were conducted to test the applicablility of Moodle, were focused on using Moodle as a learning tool in blended learning environment. The current study is considered to be significant since it sheds light on the complete shift from face-to-face learning-teaching to use Moodle as a main online platform alongside Microsoft Teams in delivering fully online classes. 


\subsection{Microsoft Teams}

Microsoft Teams is another effective online learning platform that is currently available in the market. "It is a cloud app digital hub that brings conversations, meetings, files and apps together in a single Learning Management System (LMS)" (Microsoft, 2020). It can easily be downloaded as a desktop version or a mobile application. Teachers can use features of Microsoft Teams such as scheduling meetings with students, posting assignments, sharing files, sharing screens, using the chatting box at various levels of engagement, changing participants' roles from attendees to presenters or vice versa and recording web meetings and conferences, as well as downloading all of the recordings (Allison \& Hudson, 2020; Pretorius, 2018). It can be stated that online learning materials and learners' interactions are important factors which help students successfully achieve their learning goals (Fortune et al., 2011).

Tsai (2018) predicted that, by the end of $2020,41 \%$ of the educational institutes around the world are expected to use Microsoft Teams. Martin and Tapp (2019) tested the use of Microsoft Teams to teach a group of students who were enrolled in a law module course. This module course in question teaches those students legal English and covers the main areas of its usage in typical legal situations. Similarily, Martin and Tapp (2019) stated that the implementation of Microsoft Teams has enhanced students' interactions as well as their collaborative learning experiences in online classes. More recently, Rojabi (2020) conducted a study with 28 university students in Indonesia to gain information about their perceptions towards online learning via Microsoft Teams. the majority of respondents in his study expressed their positive views toward their online learning environment. The students have confidently declared that online learning, supports their interaction as students, as well as their interaction with the teacher. Similarly, the results of another study conducted with Jordanian university students, stated that those students have positive attitudes towards the adoption of Moodle, Microsoft Teams and Zoom as online learning platforms. Students' self-studying and academic performances were significantly affected by the use of the three platforms during the COVID-19 pandemic (Alameri et al., 2020). In the Omani EFL context, no studies related to the use of Microsoft Teams as an online platform have been conducted and therefore, the current study has a considerable level of significance to the process of online learning in Oman as well as its implication in other similar language learning contexts.

\section{Aim of the Study}

The current study investigates the students' perceptions towards the use of online learning platforms, including Microsoft Teams and Moodle. It seeks to answer the following research questions:

1) How do students perceive their interaction in using Microsoft Teams and Moodle in the EFL classroom?

2) How do students perceive the learning environment in using Microsoft Teams and Moodle in the EFL classroom?

\section{Research Method}

This descriptive exploratory study involved an analysis of surveys of foundation students' perspectives on online learning via the existing learning platforms at UTAS- Salalah. One hundred students, representing the four levels in the foundation program participated in evaluating online learning, using the survey which was administered and completed by the students online via the JotForms website. Data for this study was collected through the analysis of students' perceptions based on their personal experiences with online learning. The survey, designed based upon a five-point Likert Scale format for rating questionnaire statements, related to two themes emanating from the research questions. These include students' perceptions about their interactions and learning environment, using Microsoft Teams and Moodle. The sixteen statements on the survey were sorted into the above categories for purposes of addressing the research questions. This instrument was formerly developed by Rojabi (2020) in his study on a group of Indoesian university students. The same survey questionnaire was adopted and adapted to suit the context of the present study and was modified through rephrasing the items into words that foundation students in our sample will understand, and genuinely respond to all of the items of the survey.

The reliability test was performed using the Cronbach's alpha statistical method. Based on the results of the test, the Cronbach's alpha value obtained was 0.916 . As the value is greater than 0.7 , it follows that the data obtained in this study is reliable.

\section{Findings and Discussion}

The results from the surveys with regard to perceptions of students on their interactions within online learning are graphically presented below: 
Table 1. Frequency

\begin{tabular}{lllllllll}
\hline Criteria & Item 1 & Item 2 & Item 3 & Item 4 & Item 5 & Item 6 & Item 7 & Item 8 \\
\hline Strongly Agree & 35 & 31 & 26 & 6 & 26 & 27 & 17 & 26 \\
Agree & 45 & 42 & 39 & 15 & 39 & 34 & 20 & 39 \\
Neutral & 14 & 18 & 17 & 29 & 21 & 23 & 25 & 22 \\
Disagree & 4 & 5 & 10 & 23 & 9 & 10 & 28 & 6 \\
Strongly Disagree & 2 & 4 & 8 & 27 & 5 & 6 & 10 & 7 \\
Total & 100 & 100 & 100 & 100 & 100 & 100 & 100 & 100 \\
\hline
\end{tabular}

The following eight items measure the students' interaction, while using Microsoft Teams and Moodle. The results, with regard to the students' responses on the surveys, are given in percentages, to reflect the degree of interaction that the students exhibited in the first semester, when they were taught side-by-side, using both of the aforementioned platforms simultaneously.

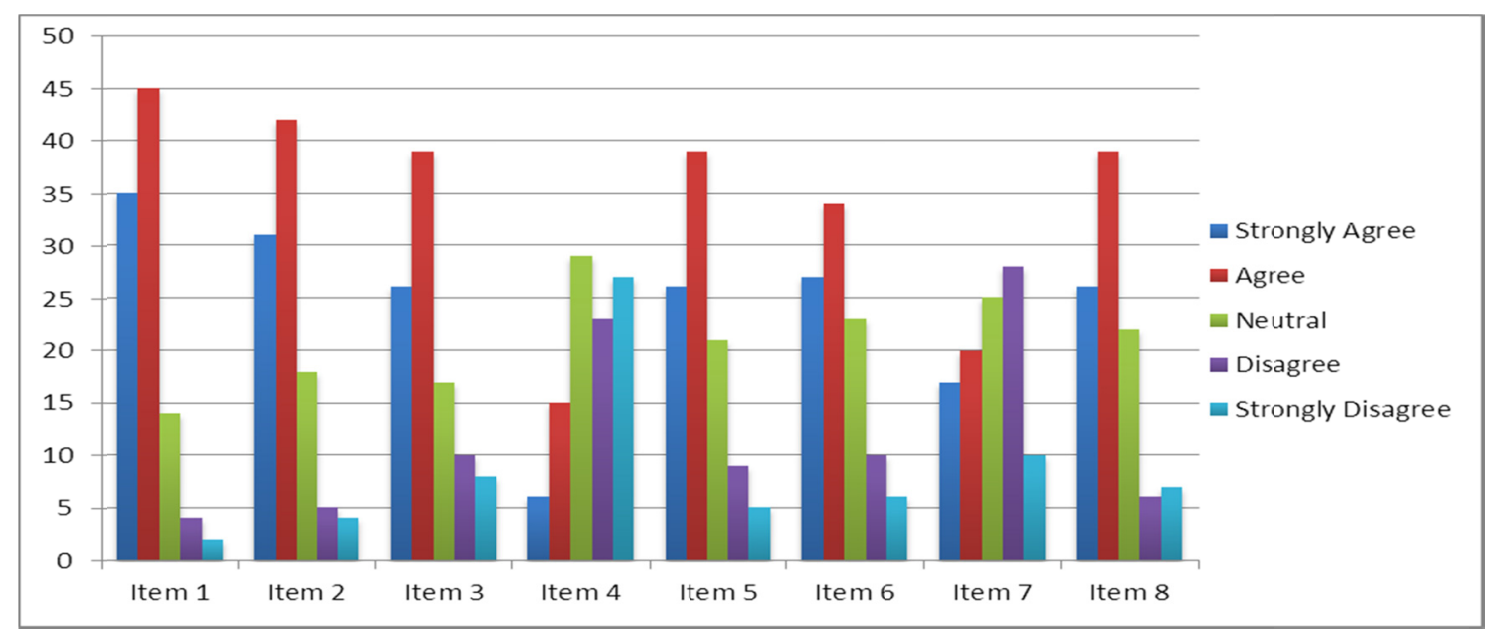

Figure 1. Students' interactions while using online learning platforms

Item 1: Online learning makes it easier for me to interact with the teacher. Approximately $80 \%$ of students agree that online learning facilitates their interaction with the teacher, $14 \%$ of students have a neutral impression of online interaction capability, while another $6 \%$ of students disagree. This shows the importance of the interactions between students and teachers. Based on this result, it can be stated that it is very significant to build some sort of communication between the students on one side, and their teacher on the other side. The enterprise of teaching and learning touches upon a number of personal dimensions and emotions, and any delivery system that enables for the teacher and student to make both pedagogical and emotional connections is significant, and may also provide for a modicum of stability. However, there is also a noteworthy lack of interaction in online classes that may be observed, as it is obvious from the students' responses, specifically, those students who disagreed that online learning does not make it more convenient for them to interact with their teacher. The physical presence of the teacher can have a calming effect on students who may already be nervous about the subject material being studied.

Item 2: Being able to interact with teachers is easier and more convenient when studying online. Around $73 \%$ of the students agreed with this premise, while $18 \%$ of the students are neutral, and another $9 \%$ express disagreement. From these responses, it can be said that most of the students don't find difficulties in getting closer to their teachers. The lack of suitable technology or related devices may also play a significant part in whatever disillusionment results, as opposed to any personal issues relating to the teacher, or the quality of the instruction given by the teacher. Some students who gave responses, disagreed due to the lesser intensity of live interaction between them and their teachers.

Item 3: Expressing the problems faced in online learning to the lecturers is more comfortable than face to face. are in accord with this statement, while another $17 \%$ of the students are neutral, and another $18 \%$ of students dissent from this statement. This percentage indicates that, while many students could face difficulty, the total 
degree of comfort enjoyed, being able to stay in their living quarters or bedrooms, in clothing that may or may not have to adhere to external standards of decorum, could outweigh whatever difficulties or ambiguities experienced from the lack of having a teacher in the same physical space. However, it should also be noted that the percentage of students disagreeing with this statement was one of the higher levels of disagreement expressed across all items responded to.

Item 4: Miscommunication between teachers and students often happens in online classes. $21 \%$ of the students concur with this item, while $29 \%$ of the students express neutral stances, and $50 \%$ of the students object. The number of students, who responded by choosing the Agree scale parameter, demonstrates that miscommunication occures because students and teachers mostly interact through written language in English like chat discussion, and it often causes miscommunication, as there is no direct face to face communication.

Item 5: Online classes make interactions between students easier. In total about $65 \%$ of the students responded positively on this statement scale points, while $21 \%$ of the students said they are neutral, compared with $14 \%$ of students who express disagreement. This situation shows that most of the students find it easy to interact with their classmates, and make more comprehensive use of the chat functions and other potential online applications, such as (perhaps) WhatsApp, to supplement whatever additional misunderstandings may result from whatever level of miscommunication exists between students and the instructor of the class. Students who disagree indicate that teachers need to find immediate remedies for such an issue that negatively affacts their interaction. For specific contexts where interaction between students is vital, such as assorted varities of teamwork, increased provisions of and solutions for this issue could prove to be vital.

Item 6: Interaction between students becomes closer in online class. $61 \%$ of the students have agreed with this concept, while $23 \%$ of the students had no opinion regarding the concept, and, $16 \%$ of the students expressed skepticism with this same situation. The majority of the students find that interaction between students becomes closer. This finding underscores the reality that students are unable to meet with, or interact with, the teacher directly, and that the students confined to their immediate living areas must rely upon their classmates, who find themselves in similar circumstances. On the other hand, few students find this kind of interaction to be difficult to maintain. It also hints at the possibility that students have found it difficult to interact virtually as they had only experienced live interaction in their previous academic semesters.

Item 7: Miscommunication between students often occurs in online classes, for example in collaborating on a jointly written group report or a group presentation. $37 \%$ of the students accepted this possibility to occur, while $25 \%$ of the students are neutral and about $38 \%$ of students challenged this assertion. For this statement, half of the students responded agree and the others disagree. Based on these responses, two things are evident: that, by the very nature of the class task involved, it will be more difficult for group- or team-based projects to function smoothly due to potential miscommunication from the lack of personal contact, and also that miscommunication among students in online classes is usually caused by weak Internet signals, which further hinder and constrain all of the possible learning outcomes.

Item 8: Overcoming complications between students becomes easier in online learning, for example in completing a group paper. $65 \%$ of students agree with this item, while $22 \%$ of the students are neutral, and $13 \%$ of the students showed their disagreement. The majority of the students find it easy to overcome the difficulties in online learning, in the process of completing a group project. However, it should be acknowledged that this condition could not be solved merely by a plurality of the students communicating with their online friends on social media websites and applications. The relatively high numbers of students expressing neutrality may also suggest that the difficulty of using online platforms was so great that they made no concerted efforts to engage in the activities or lessons that are being here reviewed.

Furthermore, the results of students' perceptions about the online learning environment are displayed below: 


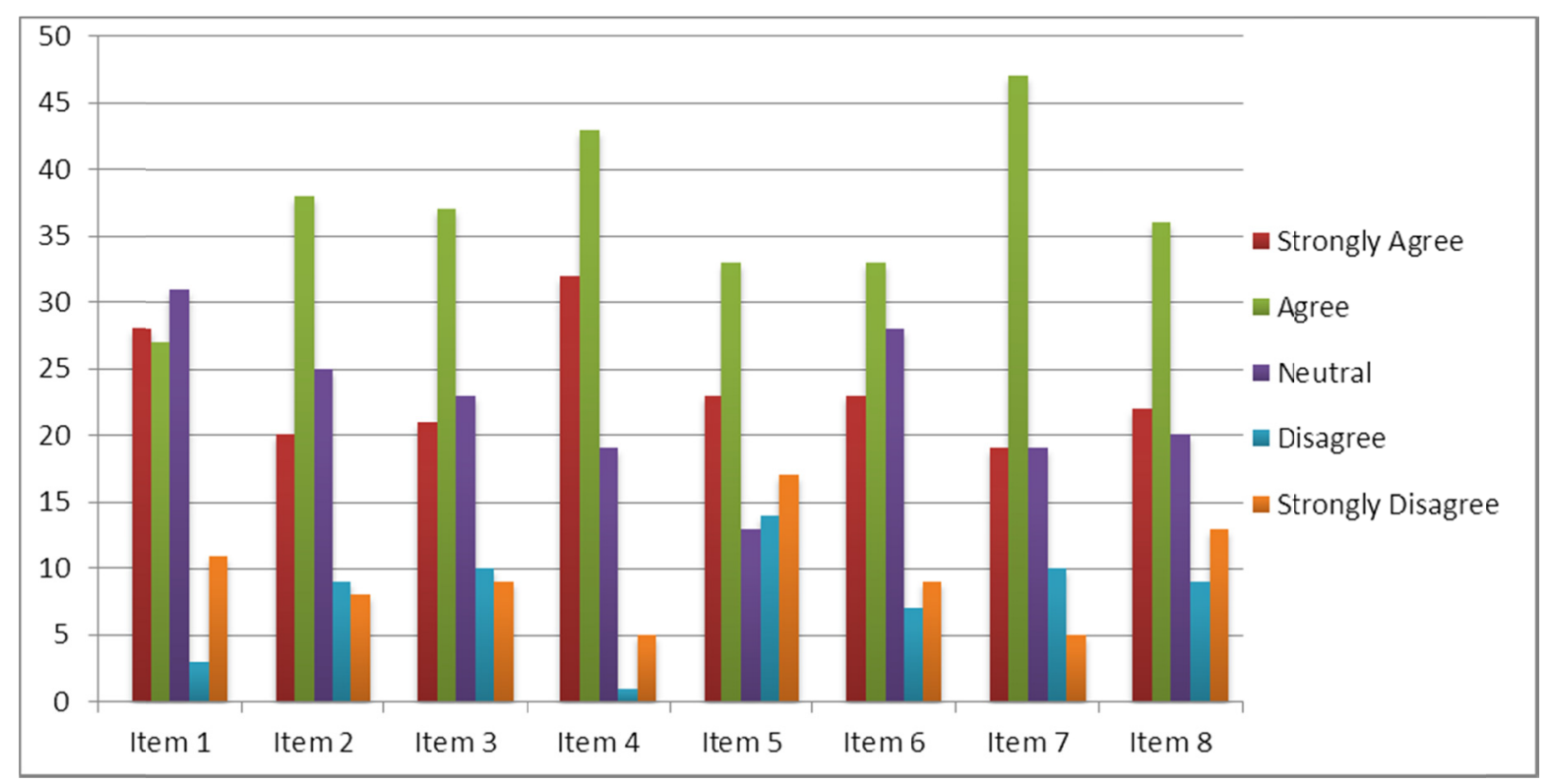

Figure 2. Students' perceptions about the online learning environment

Table 2. Frequency

\begin{tabular}{lllllllll}
\hline Criteria & Item 1 & Item 2 & Item 3 & Item 4 & Item 5 & Item 6 & Item 7 & Item 8 \\
\hline Strongly Agree & 28 & 20 & 21 & 32 & 23 & 23 & 19 & 22 \\
Agree & 27 & 38 & 37 & 43 & 33 & 33 & 47 & 36 \\
Neutral & 31 & 25 & 23 & 19 & 13 & 28 & 19 & 20 \\
Disagree & 3 & 9 & 10 & 1 & 14 & 7 & 10 & 9 \\
Strongly Disagree & 11 & 8 & 9 & 5 & 17 & 9 & 5 & 13 \\
Total & 100 & 100 & 100 & 100 & 100 & 100 & 100 & 100 \\
\hline
\end{tabular}

Item 1: The learning environment in online classes helps me to understand the materials more easily. $55 \%$ of the students expressed agreement with this sentiment, while $31 \%$ of the students said neutral, and the remaining $14 \%$ dissent. Most of the students feel that online learning can support their learning environment. The level of neutrality may reflect, once again, those students who currently live in areas where Internet signals are too weak to consistently learn, or may. For those students who disagree, there is a level of comfort they have experienced in having face to face interactions when the students face problems in acheiving their educational tasks.

Item 2: The learning environment in online class motivates me to learn and understand the materials more actively. $58 \%$ of the students concurred with this notion, while $25 \%$ of the students said neutral, and the residual $17 \%$ appear to challenge the given notion. It indicates that students have a high level of motivation for dealing with online materials. The physical absence of the teacher may have a great deal to do with the relatively high number of students who concurred.

Item 3: The learning environment in online learning leads me to prefer online learning. $58 \%$ of the students responded positively to this statement, while $23 \%$ of the students said neutral, and the remaining $19 \%$ responded negatively. This situation indicates that the majority of the students prefer the online learning. The relatively high number of respondents classifying themselves as neutral, however, suggests that further conclusions and studies may need to be drawn and conducted, respectively, for a more definite outcome to be presented. Few students responded Disagree, as it was hard for them to adapt themselves to the new features of the new learning platforms.

Item 4: I feel more comfortable answering questions in an online class. About $74 \%$ of students indicated agreement, while $19 \%$ of the students said neutral and a small grouping of $7 \%$ of the students said strongly disagree. The majority of the students felt comfortable answering questions in the class due to the high relevancy of their educational materials, provided virtually via online learning platforms, as well as the steps taken by the teachers to make their students feel at ease with communicating via a new system that is largely foreign to most of them. 
Item 5: I prefer to learn online than to learn face-to-face. $56 \%$ of the students are inclined to agree with this proposition, while $13 \%$ of the students said neutral, and $31 \%$ of the students tend to disagree. Most students prefer to learn online as online classes are more conducsive learning enivironments as opposed to live classes. The students may also have been taking into consideration their previous feelings about the ease of access to the educational system, and of preparation for the class in question. For students who responded disagree, it indicates that students face some difficulties in learning online. To take one example, students need to have a good Internet connection to enhance their learning process. Some students don't have computers or devices which facilitate the process of their learning. Alternatively, they may not live in geographic areas maximally suitable for receiving the Internet signals that would enhance their ability to hear, and receive, the online lectures.

Item 6: The learning environment in online learning gives me a large amount of motivation to study. $56 \%$ of the students assented to this principle, while $28 \%$ of the students said neutral, and $16 \%$ of students dissented. The majority of the students agreed with this question, perhaps taking into consideration all of the additional time saved by using the online model, in physically arriving to school, and preparing for real time classes, while some other students disagreed, due to some difficulties that they have faced in the online learning environment.

Item 7: The learning environment in online classes makes it easier to identify my learning needs.

One of the reasons why some students agreed is due to the ease access to online materials on the Internet. $66 \%$ of the students indicated congruence with this idea, while $19 \%$ of the students said neutral, and $15 \%$ of the students find the same idea incongruent. Few students disagreed as live interaction is of paramount importance to them more than virtual one. For those students who study deeply, studying in this way may give them more time to reflect, and to realize, what shortcomings they have, as increased responsibility for exposing themselves to study materials takes hold.

Item 8: I recommend conducting online learning in the future due to the comfortable learning environment. 58\% of the students show support for this premise. This indicates that students have comfortably experienced online classes, and they provide them with series of learning benefits as well as offer them challenges in the process. $20 \%$ of the students said neutral, and $22 \%$ show disapproval for this premise. Students disagreed with this item because they feel that their live English classes are less convenient, which can bring on a lower level of comfort.

\section{Conclusion and Recommendations}

This study has yielded an array of interesting results with regard to students' level of interaction in online classrooms, using Microsoft Teams and Moodle as the two primary learning platforms in the teaching environment. It can be concluded that a solid majority of students have expressed, via their elicited perceptions on the survey, a high level of interactive tendencies as previously reported in Rojabi's (2020) study on Indonesian university students. The online learning environment has been found to be very conducive in motivating them towards learning English through an admittedly complex and challenging framework, that not all members of a learning community can take comprehensive advantage of.

The quality of the interactions between students, and ancillary issues that came up at various points within the program, could have the undesirable effect of making the perceptions of the entire system suffer. Despite these clear indications, teachers and staff who are dedicated to meeting the needs of the students they face may be relied upon to create, and enhance, normally mundane materials and handouts to better represent the potential that online learning has to offer.

Based on the exploratory nature of the present study, it can be recommended that more studies should be conducted in the future, with a larger number of participants, ideally an entire student college population from which to gain more insightful and comprehensive findings using a mixed approach in research data collection methods, such as questionnaires and interviews. We would like to draw the attention of the concerned authorities based upon the students' responses on this study that issues such as weakened Internet signals and the quality level of wiring, desktop terminals, and a relative dearth of suitable bandwidth to serve an increasing population of teaching staff and students. The element of motivation should also be regarded as an important one, as a high level of students' motivation will more fully guarantee the achievement of optimal learning outcomes. It has been observed in this study that the level of motivation was not considerably high. As this is a new environment for the students, it may be attributable to the new learning environment in which the students have found themselves suddenly situated.

\section{References}

Ahmad, N., \& Al-Khanjari, Z. (2012). Effect of Moodle on learning: An Oman perception. International Journal 
of Digital Information and Wireless Communications, 4, 782-788. Retrieved from https://www.researchgate.net/publication/230771481_Effect_of_Moodle_on_learning_An_Oman_perceptio $\mathrm{n}$

Al Yafaei, Y., \& Attamimi, R. (2019). Understanding Teachers' Integration of Moodle in EFL Classrooms: A Case Study. English Language Teaching, 12(4), 1-6. https://doi.org/10.5539/elt.v12n4p1

Al-Ani, W. T. (2013). Blended Learning Approach Using Moodle and Student's Achievement at Sultan Qaboos University in Oman. Journal of Education and Learning, 2(3), 96-110. https://doi.org/10.5539/jel.v2n3p96

Alameri, J., Masadeh, R., Hamadallah, E., Bani, H., \& Fakhouri, H. (2020). Students' Perceptions of e-learning platforms (Moodle, Microsoft Teams and Zoom platforms) in The University of Jordan Education and its Relation to self-study and Academic Achievement During COVID-19 pandemic. Retrieved from https://www.researchgate.net/publication/344225336_Students'_Perceptions_of_E-learning_platforms_Mo odle_Microsoft_Teams_and_Zoom_platforms_in_The_University_of_Jordan_Education_and_its_Relation _to_self-study_and_Academic_Achievement_During_COVID-19_pa

Allen, I. E., \& Seaman, J. (2017). Digital learning compass: Distance education enrollment report 2017. Retrieved from the Babson Survey Research Group. Retrieved from https:/www.onlinelearningsurvey.com/reports/digtiallearningcompassenrollment2017.pdf

Allison, N., \& Hudson, J. (2020). Integrating and Sustaining Directed and Self-Directed Learning Through MS Teams and OneNote: Using Microsoft Teams and OneNote to Facilitate Communication, Assignments, and Portfolio Management. BALEAP TEL SIG Webinar, 03 Jun 2020.

Erarslan, A., \& Topkaya, E. (2017). EFL Students' Attitudes towards e-Learning and Effect of an Online Course on Students' Success in English. The Literacy Trek, 3, 80-101. Retrieved from https://www.researchgate.net/publication/321626193_EFL_Students'_Attitudes_Towards_eLearning_And_ Effect_of_An_Online_Course_on_Students'_Success_in_English_EFL_Students'_Attitudes_towards_eLea rning_and_Effect_of_an_Online_Course_on_Students'_- Success

Fortune, M. F., Spielman, M., \& Pangelinan, D. T. (2011). Students' Perceptions of Online or Face-to-Face Learning and Social Media in Hospitality, Recreation and Tourism. MERLOT Journal of Online Learning and Teaching, 7(1), 1-16. Retrieved from https://www.semanticscholar.org/paper/Students\%27-Perceptionsof-Online-or-Face-to-Face-and-Fortune-S pielman/69ec10415eb160338c5398ea0556ce427d601930

Gray, J. A., \& DiLoreto, M. (2016). The Effects of Student Engagement, Student Satisfaction, and Perceived Learning in Online Learning Environments. NCPEA International Journal of Educational Leadership Preparation, 11(1), 98-119.

Hall, B. (2003). FAQs about e-learning. Retrieved from http://www.brandonhall.com/public/faqs2/faqs $2 . \mathrm{htm}$

Martin, L., \& Tapp, D. (2019). Teaching with Teams: An introduction to teaching an undergraduate law module using Microsoft Teams. Innovative Practice in Higher Education, 3(3), 58-66. Retrieved from http://eprints.staffs.ac.uk/5613/1/Martin and Tapp 2019.pdf

Microsoft. (2020). Welcome to Microsoft Teams. Microsoft Teams [Online]. Retrieved from https://docs.microsoft.com/en-us/microsoftteams/teams-overview

Moodle. (2020). About Moodle. [Online]. Retrieved from https://docs.moodle.org/310/en/About_Moodle

O’Neill, K., Singh, G., \& O’Donoghue, J. (2004). Implementing elearning programmes for higher education: A review of the literature. Journal of Informational Technology Education, 3, 313-323. https://doi.org/10.28945/304

Pretorius, M. (2018). SharePoint and Assignments. Microsoft Teams for Education. [Online]. Retrieved from https://techcommunity.microsoft.com/t5/Microsoft-Teams-for-Education/MicrosoftTeamsAssignments-and -SharePoint-Documents/td-p/287119

Rojabi, A. (2020). Exploring EFL Students' Perception of Online Learning via Microsoft Teams: University Level in Indonesia. English Language Teaching Educational Journal, 3(2), $163-173$. https://doi.org/10.12928/eltej.v3i2.2349

Ryan, S. (2001). Is online learning right for you? American Agent \& Broker, 73(6), 54-58.

Tsai, P. (2018). Business Chat Apps in 2018: Top Players and Adoption Plans. The Spiceworks Community. [Online]. 
https://community.spiceworks.com/blog/3157-business-chat-apps-in-2018-topplayers-andadoption-plans $\% 0$ A

\section{Copyrights}

Copyright for this article is retained by the author, with first publication rights granted to the journal.

This is an open-access article distributed under the terms and conditions of the Creative Commons Attribution license (http://creativecommons.org/licenses/by/4.0/). 